\title{
Ações imperialistas dos Estados Unidos da América e a propagação da fé reformada no Brasil
}

The United States of America Imperialist Actions and the Propagation of the Reformed Faith in Brazil

Márcio Ananias Ferreira Vilela* ananiasvilela@hotmail.com

Resumo: Este artigo tem por objetivo analisar alguns momentos da presença de grupos protestantes no Brasil. Na narrativa, em seus vários tópicos, realizamos esforços para compreender a atuação de missionários presbiterianos provenientes dos Estados Unidos da América com o intuito de catequizar, e assim expandir o Presbiterianismo para várias regiões do Brasil. Podemos assim concluir que tais ações estão inseridas em uma cosmovisão imperialista em que os estadudinenses teriam o dever, quase divino, de propagar a fé reformada, levando o progresso e a civilização para outras nações.

Palavras-chaves: protestantismo, missão, imperialismo

Abstract: This article aims to analyze the presence of Protestant groups in Brazil in different moments. We attempt to understand the operation of Presbyterian missionaries from United States of America in order to catechize and hence spread Presbyterianism in several Brazilian regions. The study concludes that these actions are inserted in an imperialist worldview whereby North-American groups had an almost divine duty to propagate the Reformed Faith, thus bringing progress and civilization to other nations.

Keywords: protestantism, mission, imperialism

* Professor do Colégio de Aplicação (Cap-UFPE) e membro do laboratório História, Política, Memória, Imagem da UFPE. 


\section{Palavras introdutórias}

Por ter o Catolicismo como religião dominante desde a colonização do Brasil, a historiografia nacional não se preocupou em analisar o Protestantismo. Atualmente essa realidade tem sido alterada de maneira significativa com inúmeros historiadores e estudiosos de outras áreas do conhecimento problematizando a presença dos mais diversos grupos protestantes no Brasil.

É preciso resaltar que as dificuldades para a realização de estudos dessa natureza devem ser consideradas. Apesar da escassez documental nos arquivos sobre a temática, existem vários indícios de sua presença quando pensamos os intensos conflitos entre protestantes e algumas lideranças católicas, com registros de assassinatos, queima de templos religiosos e discursos acalorados em praça pública. Outra dificuldade reside no fato de que muitos relatos produzidos por missionários protestantes sobre sua presença no Brasil ainda são de difícil acesso, muito dos quais contidos em seus países de origem, como nos Estados Unidos da América.

Diante dessas e outras dificuldades ensaiamos estabelecer alguns marcos da presença do Protestantismo no Brasil, principalmente da comunidade presbiteriana, grupo que chega ao Brasil em meados do século XIX, sendo formada posteriormente a Igreja Presbiteriana do Brasil, instituição em plena atividade na atualidade.

\section{As várias categorias do protestantismo no Brasil}

Convencionou-se classificar a presença do protestantismo no Brasil a partir de três categorizações: protestantismo de invasão, de imigração e de missão ${ }^{1}$ (MENDONÇA, 2004). A primeira surgiu com a expansão marítima francesa durante as dinastias de Valois e
Bourbon, quando foi estabelecida na Guanabara, entre 1555 e 1567, uma colônia denominada de França Antártica, liderada pelo Vice-Almirante francês, Nicolas Villegaignon. Com a chegada dos huguenotes ${ }^{2}$, em 1557, ali foi realizado o primeiro culto protestante nas Américas, assim como a elaboração de uma confissão de fé baseada nos princípios calvinistas. Este protestantismo de invasão também foi identificado durante o controle exercido pela Companhia das Índias Ocidentais na Capitania de Pernambuco e em parte do que é atualmente a região Nordeste, entre 1630 e 1654, período em que holandeses, que em sua maioria professavam uma religião reformada, passaram a defender e praticar a tolerância religiosa nessas áreas.

Já no início do século XIX, ainda no período classificado como Colonial, os estudiosos apresentam a existência de um protestantismo de imigração, que se intensifica com a efetivação dos tratados de Aliança e Amizade e de Comércio entre a Coroa portuguesa e a Inglaterra em 1810. Esse protestantismo era assegurado pelo Artigo XII do Tratado do Comércio e Navegação e garantia aos ingleses a liberdade de realização do culto protestante, desde que observada uma série de limites, como os locais de celebração, que não poderiam assumir as formas arquitetônicas de um templo religioso, não poderiam conter sinos, assim como não era permitido que fossem feitos prosélitos. Respeitando sempre tais limites, essa liberdade religiosa também foi estendida a outros imigrantes protestantes pela Constituição do Império de 1824.

Sobre estas primeiras práticas do protestantismo no Brasil, o sociólogo Antonio Gouvêa Mendonça fez a seguinte observação "os protestantes invasores chegaram e se foram sem deixar traços. Os demais visitantes, viajantes, comerciantes e mesmo imigrantes [...], não

\footnotetext{
${ }^{1}$ O estudioso Cândido Procópio Ferreira de Camargo dividiu a presença dos protestantes no Brasil em duas categorias: protestantismo de imigração e de missão. Mas essa clássica divisão foi repensada por Antonio Gouvêa Mendonça e tem sido utilizada por vários estudiosos do protestantismo no Brasil.

${ }^{2}$ Recebia o nome de huguenotes os protestantes calvinistas franceses nos séculos XVI e XVII.
} 
chegaram a fazer do protestantismo talvez nada mais do que mera curiosidade por uma religião exótica [...]” (MENDONÇA, 2008, p. 179-180).

Seguindo um entendimento semelhante ao apresentado por Mendonça, o missionário escocês William Forsyth, afirma ter o protestantismo chegado ao Brasil no início do século XIX com os imigrantes europeus, mas este não conseguiu se transformar, naquele período, em uma força militante considerável, que deixasse marcas profundas na sociedade (FORSYTH, 2006, p. 120).

A terceira e última categoria dessa presença religiosa foi denominada de protestantismo de missão, quando as diversas igrejas protestantes dos EUA, sobretudo a partir de meados do século XIX, passaram a enviar sistematicamente missionários ao Brasil com o objetivo bem definido de propagar a fé protestante e conquistar seguidores em uma nação essencialmente católica. Trilhando as diretrizes deste protestantismo de missão, em agosto de 1859 chegou ao Brasil o jovem missionário e Pastor Ashbel Green Simonton, proveniente de igrejas presbiterianas do Norte dos EUA, enviado pela Junta de Missões Estrangeiras, localizada em Nova York. Esta, portanto, tem sido a data propagada pela Igreja Presbiteriana do Brasil para fins comemorativos, como marco inicial do presbiterianismo em território nacional (SOUZA, 2011).

\section{A presença dos missionários presbiterianos estadudinenses no Brasil: um modelo de civilização}

Em relação a essa Junta de Missões, Alderi Matos - o qual se apresentava como historiador oficial da Igreja Presbiteriana do Brasil - afirmou ter sido criada em 1837, sendo a responsável por enviar algum tempo depois vários missionários para países como Índia, Tailândia, China, Colômbia e Japão, com o objetivo de propagar o protestantismo (MATOS, 2004, p. 13).
No Brasil, mesmo diante das dificuldades iniciais, como o domínio da língua local e a reação de hostilidade por parte de setores da igreja católica, Simonton e inúmeros outros missionários norte-americanos encontraram um ambiente que possibilitou a divulgação e a implantação do protestantismo. Havia no cenário político nacional, em meados do século XIX, um forte discurso em defesa da imigração de norte-americanos e da aceitação da religião protestante.

Representando importantes setores políticos no Segundo Reinado, o influente jurista e parlamentar $\mathrm{Au}-$ reliano Tavares Bastos defendia que o Brasil deveria se aproximar dos EUA, não só nos aspectos político e econômico, mas incentivar internamente um influxo do caráter civilizador norte-americano. Além do que, apresentava duas maneiras que permitiriam ao Brasil um maior contato com o espírito civilizador da nação do Norte. A primeira era incentivando um processo migratório para o Brasil de contingentes de norte-americanos, que após a Guerra de Secessão e a derrota dos Confederados do Sul, estavam procurando na América do Sul um novo lar. Com este intuito e tendo o apoio de inúmeros políticos de tendências liberais, ajudou a estruturar a Sociedade Internacional de Imigrantes em 1866, cujo objetivo era o de realizar campanhas para estimular a imigração em massa de sulistas dos EUA para o Brasil. Defendia também, como uma eficiente maneira de ampliar o contato com a próspera civilização dos EUA, uma permissão que o Império deveria conceder aos missionários protestantes norte-americanos que àquela altura chegavam ao Brasil para difundir sua doutrina. Acreditava Tavares Bastos, que a religião protestante pudesse produzir na sociedade brasileira as mesmas transformações civilizatórias que entendia terem acontecido nos EUA (PEREIRA, 2007).

Essa demanda civilizatória pode explicar em parte o não cumprimento da Constituição de 1824, no 
que tange a temática religiosa. A esse respeito uma série de critérios e proibições era preconizada: a religião oficial do Brasil era o Catolicismo Romano; proibia entre outras coisas a realização de ações evangelizadoras com o objetivo de fazer prosélitos; pregar em língua portuguesa, assim como a construção de locais de culto que pudessem ser identificados como tais externamente. O teólogo José Roberto de Souza, que até o momento da construção dessa escrita é professor do Seminário Presbiteriano do Norte, afirmou que, de fato, a Constituição de 1824 não era observada em sua totalidade, tendo o próprio missionário presbiteriano Ashbel Green Simonton, quando chegou ao Brasil em 1859, - mas precisamente ao Rio de Janeiro, então capital do país procurado aprender o português, o que lhe possibilitou pregar e/ou evangelizar os brasileiros na língua local sem qualquer interferência das autoridades nacionais (SOUZA, 2011, p. 137-155).

A presença destes missionários presbiterianos no Brasil - protestantismo de missão - proveniente dos Estados Unidos seguiu algumas especificidades. É importante ressaltar que, desde a primeira metade do século XIX, questões como o escravismo no território norteamericano vinham provocando fortes tensões na Igreja Presbiteriana daquele país. E com os conflitos gerados pela Guerra de Secessão (1861-1865) - conhecida também, como a Guerra Civil - houve uma ruptura definitiva, surgindo no Norte, a Igreja Presbiteriana dos Estados Unidos da América (PCUSA) ${ }^{3}$, que tendia para uma postura antiescravista, e no sul, a Igreja Presbiteriana dos Estados Unidos (PCUS), descrita como mais conservadora e defensora da permanência da escravidão. (REILY, 2003, p. 128-140). Todavia tal ruptura não inviabilizou os projetos missionários destas insti- tuições. Pelo contrário, passaram a agenciar um notável esforço como o envio de recursos financeiros e humanos para o Brasil e a América Latina a partir da segunda metade do século XIX, atuação que se estende durante quase todo o século $\mathrm{XX}{ }^{4}$

Esses esforços foram agenciados tanto pela Igreja do Norte, por meio de sua Junta de Missões sediada em Nova York, como pela recém-estruturada (1861) Igreja Presbiteriana dos Estados Unidos (PCUS), cuja sede da sua organização missionária (Comitê de Missões Estrangeiras) localizava-se na cidade de Nashville, no estado do Tennessee. Assim, terminada a Guerra de Secessão, estas instituições religiosas, por meio dos setores de missões, passaram a incentivar e enviar um número significativo de pastores e missionários para várias regiões do Brasil, com objetivo de atrair os brasileiros a professarem uma nova doutrina. (REILY, 2003, p. 29).

Para o historiador francês Émile Léonard, após a derrota dos Confederados uma considerável leva de missionários cruzaram o Oceano Atlântico em direção ao Brasil. Ao mesmo tempo, o historiador afirmou que não eram apenas estes missionários que migravam. Havia outro movimento. Várias famílias protestantes do Sul dos EUA fizeram este mesmo caminho, sobretudo para a província de São Paulo (LÉONARD, 2002, p. 85). Seguindo este raciocínio, o Doutor em Teologia Duncan Reily afirmou ter sido este deslocamento, em grande medida, incentivado e reforçado por uma série de condições. Ou seja, teriam sido "atraídos pela boa terra a preços acessíveis, pelo clima e pela ajuda do governo imperial, além da possibilidade de adquirirem escravos no Brasil, o que não lhes era mais possível na sua terra de origem" (REILY, 2003, p. 129-130). Toda-

\footnotetext{
${ }^{3}$ É importante informar ao leitor que em 1958, a Igreja Presbiteriana dos Estados Unidos da América (PCUSA), formalizou uma união com a Igreja Presbiteriana Unida, acarretando na formação da Igreja Presbiteriana Unida dos Estados Unidos da América (UPCUSA), como explica NASCIMENTO, Ester Fraga Vilas-Bôas Carvalho. Educar, curar, salvar: uma ilha de civilização no Brasil tropical. Maceió: EDUFAL, 2007. p. 69.

${ }^{4}$ A presença destas Missões (presbiterianas, batista, entre outras) norte-americanas no Brasil, assim como em várias partes da América Latina, África e Ásia, ainda carece de investigações consistentes no campo da História, da Antropologia e da Sociologia.
} 
via, no que tange a temática da escravidão, é importante salientar os reflexos no Brasil dos embates que permeavam setores da sociedade nos EUA em torno da permanência ou não do trabalho escravo. Profundamente inseridos nesse conflito, havia por parte dos missionários provenientes da Igreja Presbiteriana dos Estados Unidos da América uma tendência maior para condenar a escravidão ao contrário daqueles enviados pela Igreja Presbiteriana dos Estados Unidos, cuja postura inclinava-se muito mais para uma tolerância ou defesa da escravidão. No Brasil, sinais desse confronto se fizeram presentes com o próprio Ashbel Green Simonton, enviado pela Igreja do Norte. O mesmo deixou registrado, em seu diário de viagem, várias passagens dando conta da sua posição antiescravista tanto em seu país como no Brasil. (CÉSAR, 2009, p. 115-126).

Além destes aspectos delineados até o momento, os missionários protestantes em meados do século XIX agiam motivados por uma concepção política, social e religiosa, bem demarcada, em relação ao seu papel perante o mundo, e, sobretudo, frente à América Latina. Provavelmente eles interagiam, como a maior parte dos seus contemporâneos, com uma autoimagem carregada de significados religiosos construída em torno da chegada dos puritanos ingleses nas Treze Colônias - imigrantes protestantes fugidos da perseguição religiosa do século XVII na Inglaterra. Essa percepção do povo norte-americano foi descrita por Reily da seguinte maneira:

Como Deus, por Moisés, libertou os israelitas da escravidão no Egito, pela travessia maravilhosa do Mar Vermelho, os puritanos se libertaram da opressão dos soberanos ingleses Tiago I e Carlos I, atravessando o Atlântico no pequeno navio Mayflower. Deus estabelecera seu pacto com o povo liberto, no Sinai; paralelamente, os puritanos, antes de pôr os pés em terra seca na América, firmaram o Mayflower Compact. Explicitaram que havia encetado sua viagem de colonização "para a glória de Deus, avanço da fé cristã e honra do nosso rei e país [...] solene e mutuamente, na presença de Deus, e cada um na presença dos demais, compactuamos e nos combinamos em um corpo político civil". Finalmente, como Josué havia conquistado a terra da promissão, os americanos viam como seu "destino manifesto" conquistar o Continente de oceano a oceano, espalhando os beneficios de uma civilização republicana e protestante por toda a parte. Assim, os Americanos do Norte observavam, jubilosos, o início do processo da libertação da América Latina [...]. (REILY, 2003, p. 37).

Este imaginário religioso de uma civilização escolhida diante de um pacto feito com Deus ainda durante a travessia para uma terra distante, ao norte da America - dentre outras construções tendo por base todo um simbolismo religioso e moral -, foi incorporado à sociedade norte-americana. Mentalidade essa que seria extremamente utilizada em meados do século XIX para fundamentar o que ficou conhecido como $O$ Destino Manifesto, movimento que consolida as bases teóricas (moral, cultural e ideológica) para a conquista de novos territórios e povos. Este movimento era a sistematização da crença na qual os anglo-saxões, ou seja, o povo branco norte-americano se autoafirmava como uma raça superior ajudada por Deus; que a religião protestante era o verdadeiro caminho rumo ao paraíso, o que lhes garantia o direito e/ou a obrigação cristã de regenerar os povos atrasados (MENEZES, 2010, p. 19$20,56)$.

Neste sentido, a crença fortemente alicerçada em torno de um povo eleito e/ou escolhido por Deus integrava e/ou interagia com o imaginário artístico norte-americano, sendo por esse retratado. É dessa maneira que entendemos uma série de caricaturas produzidas nos séculos XIX e XX, tendo circulado na imprensa, sobretudo em periódicos e revistas. O cientista político John Johnson no livro Latin America in Caricature (1980), analisou - fazendo uso de caricaturas - a mentalidade recorrente sobre o papel político que os EUA 
deveriam desempenhar para com seus vizinhos. Como mostrou Alberto Del Castillo, a produção de imagens interage, participa de esquemas sociais em circulação em um dado momento (2006, p. 32). Analisando a imagem usada por Johnson com base nessas considerações, podemos afirmar que ela não se encontra fora de um código cultural, legitimado por importantes setores sociais norte-americanos, sobretudo protestantes. $\mathrm{Ou}$ seja, a imagem emitia uma linguagem visual carregada de sentidos e significados aos leitores daqueles periódicos.

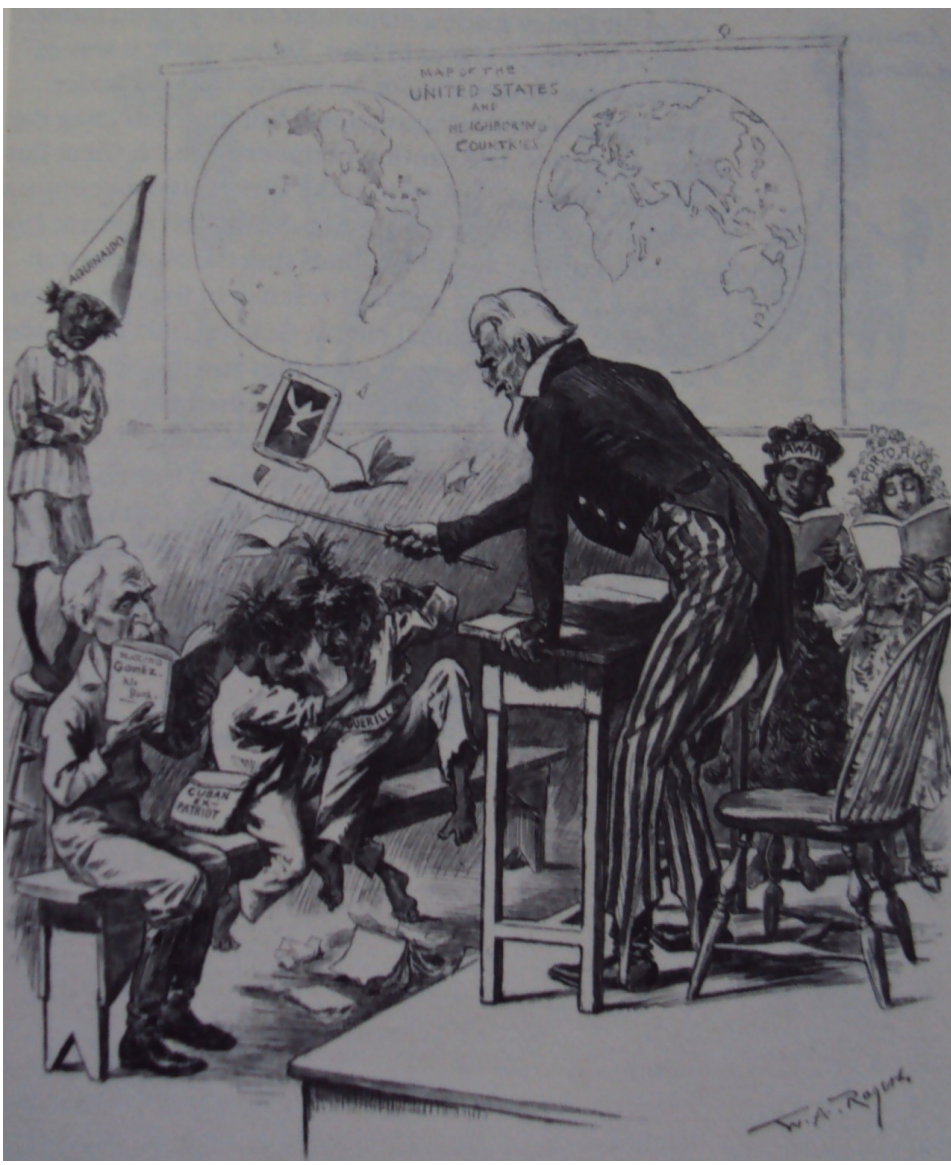

Figura 1 - Caricatura de William Allan Rogers. Fonte: Harper's Weekly, Nova York, 27 ago. 1898 apud JOHNSON, John J. Latin America in caricature. Austin: University of Texas Press, 1980. p. 217

Um dos cartunistas do jornal Harper's Weekly, William Rogers, projetou o seu olhar sobre a América Latina e o papel exercido pelos EUA, este, portando uma estatura imponente e bem vestido, características que correspondiam à moderna e avançada civilização protestante do Norte. A sua imagem é a de quem ensina e civiliza os povos da América Latina, o que tinha acontecido com alguns países, os quais foram representados por pessoas de aspectos mais adultos e de comportamentos exemplares, estando bem vestidas. Já a América Latina é retratada como sendo ainda uma criança rebelde e carente, que se encontrava descalça e mal vestida. E, como toda criança, ela deveria ser educada e/ou civilizada, processo que muitas vezes só era possível com a utilização da força e o disciplinamento constante. Não é, então, por acaso que o caricaturista projetou os EUA fazendo uso de um chicote pronto para disciplinar e orientar os países rebeldes da América Latina.

Caricaturas semelhantes, nas quais a América Latina e seus aspectos políticos, econômicos e sociais foram representados a partir de um código cultural e/ou uma concepção de mundo fortemente aceita, eram bastante comum circularem nos jornais e revistas dos EUA em vários outros momentos. (JOHNSON, 1980; PORFÍRIO, 2009, p. 59-74). Os missionários norteamericanos, portanto, não estavam fora desse código cultural. O teólogo e filósofo Rubem Alves afirmou que tais agentes ao chegarem ao Brasil em meados do século XIX sempre se comportaram como os representantes de uma cultura tida como civilizada e superior, em detrimento da cultura nacional e da religião católica aqui consolidada (ALVES, 2005; DUPAS, 2009, p. 7-39).

\section{A formação da Igreja Presbiteriana do Brasil: estrutura e organização}

Paralelamente, não podemos desconsiderar o papel desempenhado por estes missionários na estruturação (material, doutrinária e organizacional) do que

\footnotetext{
${ }^{5}$ Harper's Weekly era uma publicação de política semanal da cidade de Nova York que circulou entre 1857 até 1916, também intitulado de O Jornal da Civilização. Apresentava notícias nacionais e internacionais, ficção, ensaios diversos, e humor, ao lado de ilustrações. De ampla circulação nos Estados Unidos, tinha como importante características a produção de ilustrações, ou seja, de charges políticas. Disponível em: <http://en.wikipedia.org/wiki/ Harper's_Weekly>. Acesso em: 31 de maio de 2013.
} 
hoje conhecemos como Igreja Presbiteriana do Brasil. Logo após a chegada do primeiro missionário, Ashbel Simonton, em 1859, os esforços da Igreja Presbiteriana dos Estados Unidos da América (PCUSA), igrejas do Norte dos EUA, resultaram no surgimento das três primeiras igrejas presbiterianas localizadas em importantes centros urbanos da época: na cidade do Rio de Janeiro em 1862, em São Paulo em 1865 e em Brotas/SP em 1865. Tal crescimento, portanto, não se encontrava desarticulado do trabalho missionário desenvolvido pela Missão do Brasil - subordinada a Junta de Missões de Nova York (PCUSA) - que atuava inicialmente nos estados do Rio de Janeiro, São Paulo e extremo sul de Minas Gerais; posteriormente, sua inserção atingiria os estados do Paraná, Santa Catarina, Bahia e Sergipe.

Objetivando abranger a maior parte do território nacional, em 1896 a Missão do Brasil foi dividida administrativamente em: Missão Sul do Brasil (RJ, PR, SC) e Missão Central do Brasil (BA, SE e norte de MG). Ao mesmo tempo, o Comitê de Missões Estrangeiras, ligado a Igreja Presbiteriana dos Estados Unidos (PCUS), igrejas do Sul dos EUA, concentraram seus esforços no Nordeste do estado de São Paulo, Sudeste de Minas Gerais e Triângulo Mineiro. Estendia-se também a partir de uma vasta área do Nordeste acima do rio São Francisco: de Alagoas até a Região Norte do Brasil, na Amazônia (MATOS, 2004, p. 13-20). Seguindo o exemplo anterior, em 1896 dividiu seu corpo missionário em: Missão Norte do Brasil (Norte e Nordeste) e Missão Sul do Brasil (SP, MG, GO). Em 1906 esta última também sofre divisões formando: a Missão Oeste do Brasil, com sede na cidade de Campinas e a Missão Leste do Brasil, sediada na cidade de Lavras/ MG.
A atuação desses missionários, ligados à Igreja Presbiteriana do Sul dos EUA (PCUS), garantiu o surgimento de uma série de igrejas presbiterianas, possibilitando em 1872 a criação do Presbitério de São Paulo que, extinto em 1877, foi reorganizado em 1887 como Presbitério de Campinas e Oeste de Minas. E no Nordeste destacou-se a criação em 1888 do Presbitério de Pernambuco. Anteriormente, a Igreja Presbiteriana do Norte dos EUA (PCUSA) tinha como objetivo melhor coordenar suas igrejas: Igreja Presbiteriana de São Paulo, do Rio de Janeiro e de Brotas formou em dezembro de 1865 o Presbitério do Rio de Janeiro, mas este estava subordinado ao Sínodo de Baltimore - uma importante cidade do estado de Maryland (MATOS, 2004, p. 13-20).

É preciso mencionar que toda essa estrutura que começava a ser organizada estava subordinada às igrejas presbiterianas dos EUA, seja do Norte ou do Sul, como popularmente ficaram conhecidas. Não havia, portanto, uma igreja presbiteriana nacional. Essa realidade só começou a ser alterada com o surgimento do Sínodo do Brasil em 6 de setembro de 1888, a partir da agremiação do Presbitério do Rio de Janeiro, de São Paulo e Oeste de Minas e de Pernambuco. Segundo Alderi Matos, o surgimento do "Sínodo representou a autonomia eclesiástica do presbiterianismo brasileiro, até então jurisdicionado às igrejas-mães norte-americanas". (MATOS, 2004, p. 15-16). ${ }^{6}$

A partir deste momento, as igrejas estruturadas pela PCUSA e PCUS foram incorporadas à Igreja Presbiteriana do Brasil (IPB), acarretando, pelo menos em termos formais, uma maior autonomia. A formação desta igreja presbiteriana nacional foi analisada por Duncan Reily, para o qual "os missionários presbiterianos, desde a autonomia (1888), foram arrolados como

\footnotetext{
${ }^{6}$ Ver também ARNOLD, Frank L. Uma longa jornada missionária. São Paulo: Cultura Cristã, 2012. p. 50-51.
} 
ministros da nova Igreja Nacional” (REILY, 2003, p. 173). Porém, os missionários continuaram a participar de uma organização paralela, a Missão. Assim, os missionários norte-americanos passaram a pertencer a Igreja Presbiteriana do Brasil mas a sede da sua Missão estava nos EUA. Não houve, no entanto, um desligamento integral, as missões tinham certo grau de ingerência na IPB e compartilhavam a sua condução.

A busca por uma maior autonomia gerou profundos embates entre a IPB e os missionários norteamericanos, levando a formulação de um acordo intitulado Modus operandi ou Brazil Plan em 1917. Este documento, entre outras regulamentações, garantiu as missões norte-americanas suas permanências e a continuidade do trabalho missionário desenvolvido no Brasil, mas, sobretudo, regulamentava as condições em que os missionários deveriam atuar, assim como os limites de sua participação em Presbitérios e na condução de igrejas locais (REILY, 2003, p. 173-177; LÉONARD, 2002).

Paralelamente ao seu crescimento - com o surgimento de novas igrejas, Presbitérios e Sínodos e a busca por autonomia em relação às igrejas norteamericana -, a estrutura administrativa da Igreja Nacional, conhecida como presbiterianismo, pouco a pouco, foi se consolidando. É preciso mencionar que o presbiterianismo se trata de um sistema de governo eclesiástico que se originou na Escócia, no contexto da Reforma Protestante do século XVI, tendo migrado posteriormente para América do Norte (Treze Colônias), trazido pelos protestantes ingleses que fugiam da perseguição religiosa na Inglaterra no século XVII. No Brasil, salvo algumas particularidades, a igreja implantada por estes missionários seguiu esta mesma estrutura de governo regida por concílios.

\section{ESTRUTURA FUNCIONAL DOS CONCÍLIOS DA IPB}

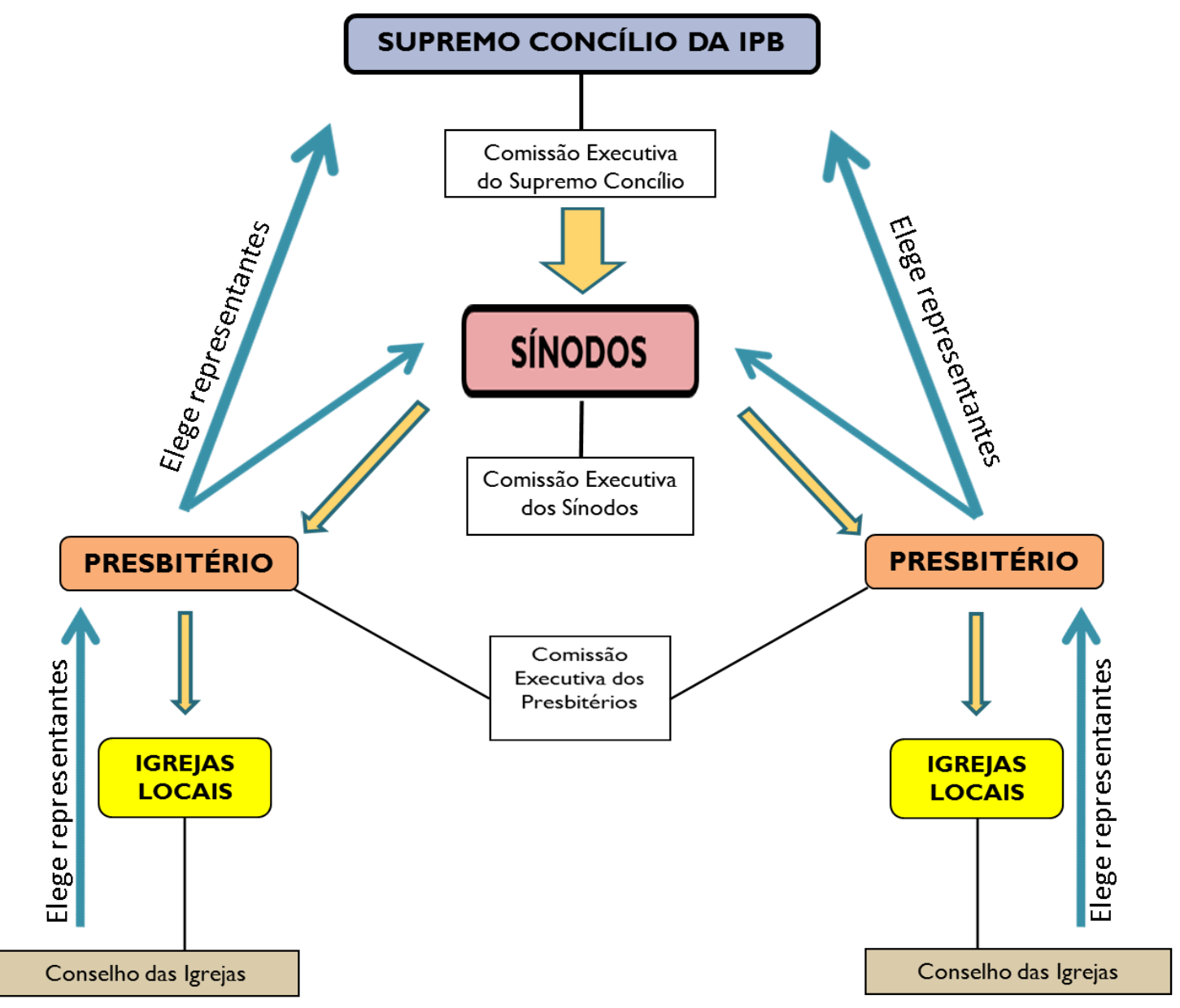


Como podemos compreender por meio do organograma apresentado, a IPB é regida obedecendo a uma hierarquia de Concílios: Conselhos, Presbitérios, Sínodos e o Supremo Concílio. ${ }^{7}$ É nas igrejas locais que os membros convertidos, muitos deles ex-católicos, começam a conhecer esta estrutura verticalizada. Para ser aceito como membro efetivo, o novo convertido é acompanhado pela comunidade a qual pretende ingressar e deverá, posteriormente, ser submetido a uma cerimônia religiosa conhecida como profissão de fé. Neste ato o fiel terá que prometer solenemente, entre outras coisas, o respeito incondicional às autoridades religiosas constituídas. Com este ritual, é recebido por toda a igreja local como um membro comungante, ou seja, estará apto a receber todos os sacramentos, como a ceia, onde é lembrada a morte de Jesus Cristo.

Após este momento estará aberta a possibilidade para que o mesmo participe ativamente - junto com o pastor - da administração da igreja a qual pertence. Todas as igrejas presbiterianas locais são comunidades administradas por um Conselho formado geralmente por três presbíteros mais o pastor, que também assume a função de presidente. Os presbíteros poderão ser indicados pelo próprio Conselho ou pela comunidade de membros, ou seja, a igreja local. Mas neste último caso, deverão ter seus nomes também aprovados por este Conselho para só assim, concorrer ao cargo e ser eleito pelo voto secreto da comunidade (homens e mulheres) por uma maioria simples, para um mandato de cinco anos. Comumente o processo eleitoral é realizado para complementar o número de presbíteros cujo mandato vai sendo expirado.
Um conjunto de no mínimo três igrejas de uma cidade ou região formará um Presbitério, como prever o Manual Presbiteriano ${ }^{8}$. Em cidades com grande número de igrejas é comum existirem vários Presbitérios, como também poderá ser formado por igrejas de várias cidades. Integram estes Presbitérios, os quais também são Concílios, os representantes destas igrejas locais acompanhados de seus pastores ${ }^{9}$, que se reúnem ordinariamente ao início de cada ano. $\mathrm{O}$ primeiro ato quando reunidos é formar uma Mesa Executiva do Presbitério, composta por um Presidente, Vice-Presidente, $1^{\circ}$ e $2^{\circ}$ secretários e o Tesoureiro, que serão responsáveis pela realização do concílio. Em outros momentos, quando necessário, essa Mesa poderá se reunir, sendo agora nomeada por Comissão Executiva do Presbitério. Quando existe um grande número de Igrejas e consequentemente de Presbitérios, há a possibilidade de organizar mais de um Sínodo por Estado. O contrário também é possível, um Sínodo pode ser formado pelos Presbitérios de mais de um Estado. Os Sínodos que também são Concílios que se reúnem ordinariamente a cada biênio, nos anos ímpares, quando há a composição de uma Mesa Executiva do Sínodo, que assim como nos presbitérios, se reunirá como Comissão Executiva do Sínodo sempre que necessário for.

O Supremo Concílio da Igreja Presbiteriana ${ }^{10}$ ocorre quando os representantes de cada presbitério (composto de dois pastores e dois presbíteros, que neste momento são nomeados de deputados), sob a chancela dos seus respectivos Sínodos, reúnem-se ordinariamente nos anos pares a cada quatro anos. Há também a possibilidade de reuniões do Supremo Concílio (SC) em

\footnotetext{
${ }^{7}$ Toda esta estrutura dorsal de Concílios é composta apenas por homens. As mulheres participam e poderão administrar outras instâncias menores que compõe a instituição.

${ }^{8}$ Há vários documentos que regem a Igreja Presbiteriana do Brasil. A Igreja tem como única regra de fé e prática a Bíblia, tendo adotado os símbolos de fé elaborados pela Assembleia de Westminster em 1646 na Inglaterra. Existe também o Manual Presbiteriano, que é composto por três partes: a Constituição da IPB (que trata da forma de governo); o Código de Disciplina (que diz respeito as regras de conduta), e os Princípios de Liturgia (que versa sobre a vida devocional da instituição).

${ }^{9}$ É importante mencionar que os pastores não são membros das igrejas as quais exercem seus ofícios, mas do Presbitério que jurisdiciona tais igrejas, como estabelece o Manual Presbiteriano.

${ }^{10}$ Supremo Concílio é uma designação que surgiu a partir de 1937, antes desse momento, este Concílio se chamava Assembleia Geral, a exemplo dos EUA.
} 
caráter extraordinário. Para conduzir os trabalhos é eleita uma Mesa Executiva do Supremo Concílio composta por Presidente, Vice-Presidente, Secretário Executivo, $1^{\circ}$ e $2^{\circ}$ secretários e Tesoureiro, que permaneceram em atividade durante os quatro anos seguintes, até a realização de uma nova reunião. Ao mesmo tempo, para dar continuidade a esta administração, há uma Comissão Executiva do Supremo Concílio que é formada pela Mesa Executiva do SC (Presidente, Vice-Presidente, Secretários e Tesoureiro) mais os representantes dos respectivos Sínodos. Esta Comissão se reúne ordinariamente a cada ano, com possibilidades de se reunirem extraordinariamente.

No que se refere ao Supremo Concílio, este tem por competência legal, entre outras atribuições, analisar e julgar as demandas provenientes dos concílios inferiores, além de "formular sistemas ou padrões de doutrina, quanto à fé; estabelecer regras de governo, de disciplina e de liturgia, de conformidade com o ensino das Sagradas Escritura; [...] definir as relações entre a Igreja e o Estado”. (MANUAL PRESBITERIANO, 1997, p. 36).

É em suas reuniões que se apresentam e efetivam as maiores discussões sobre o andamento da Igreja; ao final, suas resoluções são divulgadas em documentos institucionais, espécie de anais denominados Digestos Presbiterianos $^{11}$, assim como as decisões da Comissão Executiva do SC.

Esse conjunto de resoluções, a depender do grau de debates que o envolvia, era publicado também no jornal oficial da IPB - designado em meados do século XX de jornal Brasil Presbiteriano - o que possibilitava a divulgação de tais decisões à significativa parcela de pessoas ligadas à Igreja; decisões que deveriam funcionar como um tipo de lei e, assim, serem observadas por todos indistintamente. (MANUAL PRESBITERIANO,
1997; GIESBRECH, 2002). São determinações que poderão ser observadas, por exemplo, a partir de suas concepções sociais e políticas, nas suas relações com a Igreja Católica Romana e outras igrejas protestantes e nas suas convicções em torno de instituições ecumênicas, como o Conselho Mundial de Igrejas (CMI) e o Conselho Internacional de Igrejas Cristãs (CIIC).

É importante mencionar, para concluir este texto, que todas essas decisões/determinações são possíveis de serem analisadas, mas para tanto, carecem de um maior aprofundamento investigativo sobre a Igreja Presbiteriana do Brasil. Dito de outra maneira, novas viagens a outros tempos serão necessárias. Registros importantes para compreender essa instituição a partir de meados do século XX quando se observa uma maior intensificação em relação a estas questões, tendo em vista, os embates políticos e sociais que estão se agigantando no Brasil, e tem como auge dessa crise o golpe civil e militar de 1964. Mas essa é uma outra história.

\section{Considerações finais}

Ao longo desse artigo procuramos compreender como se deu a presença protestante no Brasil, a chegada e atuação dos missionários provenientes dos Estados Unidos e a formação da Igreja Presbiteriana do Brasil. Procuramos, entretanto, escapar de uma análise que tão somente relata a chegada desses missionários sem problematizar aspectos importantes como o imperialismo. Esses missionários tinham a concepção de que ao propagar a fé reformada estariam contribuindo para transformar o Brasil em uma nação civilizada; segundo essa mesma concepção, o Catolicismo era entendido como formador de uma cultura e de um povo atrasado. Era preciso construir outra cultura, voltada para o progresso, e sobre isso - na visão desses missionários - os EUA era um exemplo para a América Latina.

\footnotetext{
${ }^{11}$ Estes anais são publicados pela Casa da Editora Presbiteriana com o título Digesto Presbiteriano: Resoluções do Supremo Concílio da Igreja Presbiteriana do Brasil e da sua Comissão Executiva, e poderão ser facilmente localizados nas bibliotecas dos seminários e em algumas igrejas.
} 


\section{Referências bibliográficas}

ALVES, Rubem. Religião e repressão. São Paulo: Loyola, 2005.

ARNOLD, Frank L. Uma longa jornada missionária. São Paulo: Cultura Cristã, 2012. p. 50-51.

CÉSAR, Elben M. Lenz. Mochila nas costas e diário na mão: a fascinante história de Ashbel Green Simonton. Viçosa, MG: Ultimato, 2009. p. 115-126.

COSTA, Priscila Borba. O Destino Manifesto do povo estadunidense: uma análise dos elementos delineadores do sentimento religioso voltado à expansão territorial. In: Congresso Internacional de História, 5, 2011, Maringá. Anais... Maringá: UEM, 2011. p. 2267-2276.

DEL CASTILLO TRANCOSO, Alberto. Conceptos, imágenes y representaciones de la niñez em la ciudad de México, 1880 - 1920. México - DF.: El Colégio de México, Centro de Estudios Históricos; Institutos de Investigaciones Dr. José María Luis Mora, 2006. p. 32.

DUPAS, Gilberto. Religião e Sociedade. In: SILVA, Carlos Eduardo Lins da (Org.). Uma nação com alma de igreja: religiosidade e políticas públicas nos Estados Unidos. São Paulo: Paz e Terra, 2009. p. 07-39.

FORSYTH, William B. Jornada no Império: vida e obra do Dr. Kalley no Brasil. São Paulo: Fiel, 2006. p. 120.

GIESBRECH, Érica. Fiéis em fuga? A nova configuração da Igreja Presbiteriana do Brasil. Dissertação (Mestrado em Antropologia) - Instituto de Filosofia e Ciências Humanas, Universidade Estadual de Campinas, Campinas, 2002.

JOHNSON, John J. Latin America in caricature. Austin: University of Texas Press, 1980.

LÉONARD, Émile G. O protestantismo brasileiro: estudo de eclesiologia e história social. São Paulo: ASTE, 2002. p. 85.

Manual Presbiteriano. São Paulo: Editora Cultura Cristã, 1997. p. 36.

MARTINO, Luís Mauro Sá (Orgs.). Sociologia da religião e mudança social: católicos, protestantes e novos movimentos religiosos no Brasil. São Paulo: Paulus, 2004. p. 49-79;

MATOS, Alderi Souza de. Os pioneiros presbiterianos do Brasil. São Paulo: Cultura Cristã, 2004. p. 13.

MENDONÇA, Antonio Gouvêa. Protestantismo brasileiro, uma breve interpretação histórica. In: SOUZA, Beatriz Muniz;

MENDONÇA, Antonio Gouvêa. O celeste porvir: a inserção do protestantismo no Brasil. São Paulo: EDUSP, 2008

MENEZES, Alfredo da Mota. Ingênuos, pobres e católicos: a relação do EUA com a América Latina. Rio de Janeiro: Fundo de Cultura, 2010. p. 19-20 e 56.

MESQUIDA, Peri. Educação protestante e processo civilizador na América Latina: de facundo ao solitário. In: Simpósio Internacional - Processo Civilizador, 10, 2007, Campinas. Anais... Campinas: UNICAMP, 2007.

NASCIMENTO, Ester Fraga Vilas-Bôas Carvalho. Educar, curar, salvar: uma ilha de civilização no Brasil tropical. Maceió: EDUFAL, 2007. p. 69.

PORFÍRIO, Pablo F. de A. Medo, comunismo e revolução: Pernambuco (1959-1964). Recife: Ed. Universitária da UFPE, 2009. p. 59-74.

PEREIRA, Rodrigo Nóbrega Moura. A nação brasileira e o protestantismo: religião e americanismo no projeto nacional de Tavares Bastos. Revista Intellectus, Rio de Janeiro, ano 06, v. II, 2007;

REILY, Duncan Alexander. História documental do protestantismo no Brasil. São Paulo: ASTE, 2003. p. 128 140.

SOUZA, José Roberto. Mapeamento histórico do(s) protestantismo(s) em terra brasilis: o protestantismo de missão e a contribuição de Ashbel Green Simonton. Revista Paralellus, Recife, ano 02, n. 04, p. 137-155, 2011.

VILELA, Márcio Ananias Ferreira. Discursos e práticas da Igreja Presbiteriana do Brasil durante as décadas de 1960 e 1970: diálogos entre religião e política. Recife: EdUFPE, 2015. 